\title{
A tribrid Paradigm against Inundation wild animal attack and fire disasters
}

\author{
B. Annapurna, Raushan Kumar Singh, J. Saravanan, Durai Pandurangan
}

\begin{abstract}
In recent years the whole world witnessed several natural and manmade disasters. 2015 Earthquake in Nepal and India with 7.8 magnitudes which killed 9000 people and injured 22000 as per Government Records. 2018 Flood in North Korea left 10,700 people as per the report of International Federation of Red Cross (IFRC) and Wikipedia. Floods in India 2018, killed more than 300 in the state of Kerala. 2016, Forest fire in Uttarakhand, India burnt 10,000 acres of Forest area. In between April 2014-May 2017, 1,144 people killed by wild animals as per the report of Indian Environment Ministry (IEM). All the reports stated above represents indications that regardless of several advancements and technical skill development to disaster management is not considered efficiently worldwide. There are plenty of disasters which could be taken care of much efficiently and wisely. If we see the disasters like flood, fire and animal attack we can easily notice that they are manageable to much extent with expert technical advancements. Our paper is about the disaster management of the tribrid series (Flood, Fire, Wild Animal Attack) with the eminent usage of technology. We create a flood sensing unit, a fire detection unit, and a wild animal detection unit with the help of sensors and we create the alert and remedial action unit to protect the common men from sub disasters. We use Embedded and IOT technologies together to provide worldwide coverage and accurate detection of the calamities.
\end{abstract}

Index Terms: International Federation of Red Cross (IFRC), Indian Environment Ministry (IEM), tribrid series

\section{INTRODUCTION}

The sensor and microcontroller technology boosted up the inventions for advanced development and implementation. The technology is much smarter and powerful compared to once it was. With the release of sensors which can feel different natural phenomenon like heat, mass, speed, time, magnetic field, turbidity, humidity, air pressure etc the embedded system became much smarter. There are even the sensors which can sense the biological, biomedical, and human-related parameters. Much smarter microcontrollers made the sensor technology much efficient for practical usability. With the development of wireless transmission system like IoT, Zig bee, RF and GSM the sensor, microcontroller developed the reporting system as well. Disaster management is the domain which is way life-threatening for human. Several errors are also possible in manual calculations.

Revised Manuscript Received on December 30, 2019.

Dr B. Annapurna, Assoc. Prof. in Computer Science and Engineering Aditya College of Engineering, Surampalem, East Godavari Dt., AP, India.

Mr Raushan Kumar Singh, Technical Director, Spectrum Solutions, Pondicherry, India.

Mr J. Saravanan, lecturer in Bule Hora University, Ethiopia

Mr. Durai Pandurangan, Lecturer in Department of Electrical and Computer Engineering, Wachemo University (WCU), Hossana, Ethiopia.

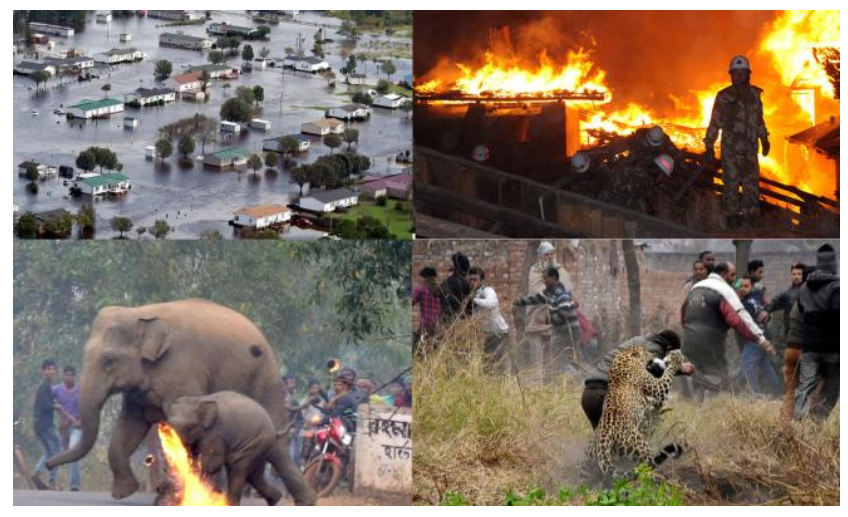

Fig. 1.1 - Overall Problem Identification

There is a strong need for technological advancement for disaster management. Several natural and manmade calamities can be predicted, reported and even controlled by the use of Sensors, Microcontrollers and communication system. We mainly deal with the calamities like flood, wild animal attack and fire. These are the most common threats and often takes place world wild. We take the scenario of a village where flood, fire and animal attacks are common.

\section{LITERATURE SURVEY}

[1]. Mrs P. Lakshmi Prasanna, Mrs B. Annapurna etc. explained in their paper "An IoT Approach to Wildfire Detection and Remedy with Sensor Network Deployment “ about wildfire detection system using LM35 temperature sensors network which is distributed in the forest to detect the uncertainty in temperature. The forest region where the temperature above the threshold limit set in the microcontroller is considered the wildfire affected zone. This location is reported to the concerned authority using the IoT coverage. The water pump is installed with control by microcontroller logic. Whenever the fire is detected then the motor gets on and sprinkles the water on fire. This can protect the forest from being burnt. Meanwhile, the IoT system reports the overall disastrous scenario to the forest department. This paper is somewhat similar to our proposed system's one part but in our concept, we use a better system with multiple functionalities. The survey helped us to understand the scenario of fire detection and alert.

[2]. J. Saravanan, A. Clement Raj, Raushan Kumar Singh etc. explained in their paper "An Efficient Security Implementation with Power Cane for Visually Challenged " about a blind stick designed to protect the blinds using the 


\section{A tribrid Paradigm against Inundation wild animal attack and fire disasters}

power booster device. This device is a portable battery-operated electric shock device. The device can boost enough electricity to give a heavy shock to the culprit without killing them. This gave us the idea to make use of this power arc device to be used in our project to create the smart fence in order to safeguard the region against wild animal attack. The power boost up takes place from a small $9 \mathrm{~V}$ battery which can be a normal rechargeable or use and throw type. The booster is sufficient for animal shock and produces enough sound to scare the animal mostly. This leads the animal getting back to woods without even getting the electric shock.

[3]. AzlinaIdris, Noridayu Mohd Noor Arif etc. explained in their paper "Smart alert flood system using GSM " about flood detection and alert system in which he used Ultrasonic $\mathrm{HC}$-SRO4 sensor which could detect the level of water. If the water crossed beyond the red zone then it used to send the SMS using the GSM modem to the rescue team of the disaster. This was a reliable system. We used the float sensor instead of the ultrasonic sensor due to its long life and mechanical properties. Mechanical components can work better compared to electronics components in case of water and moisture. It can work when it's even totally submerged in the water. This gave us the path to think about the flood detection system.

Next section deals with the proposed approach taken to create the tribrid disaster management system. We went through the drawbacks and issues in already available systems to come to a system which is much efficient and reliable to use.

\section{PROPOSED IMPLEMENTATION}

Our proposed technology can be used for individual usage as well as for all three functionalities at a time. At first, we deal with a flood by applying flood sensors on the flood-affected areas.

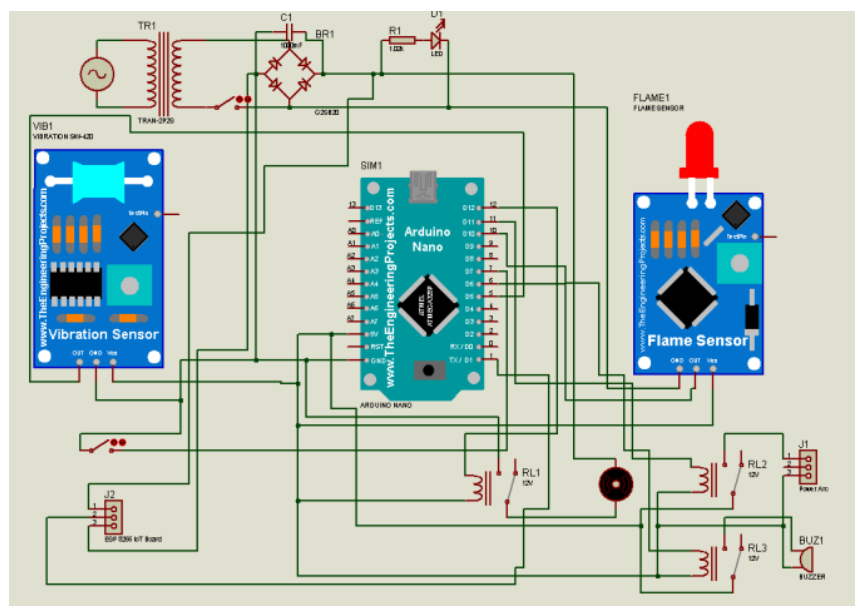

Fig. 3.1 - Overall System Circuit Diagram

Whenever the water reaches above the dangerous line the system starts the siren to alert the villagers. Flood creates the maximum damage due to late alert to people if they get alerted on time they can easily evaluate the safer locations. We also deploy IOT system to upload warning message with the geographical location on the department of Disaster Management website. The team can further help people and it

can solve the flood issue much easier. The second disaster we deal with is the fire which burns forests, villages, agricultural fields and damage several lives. The recent fire in Uttarakhand, India, Africa etc. demonstrated the destructive capabilities of fire. To tackle that we can use the flame or temperature sensor which can detect fire and heat very accurately. Once the rising temperature or flamed is sensed it automatically buzzes the siren, starts the motors to spray water, cuts the power supply of the area and uploads the location of the fire to fire fighter's website. This system can be installed in a small area like a building and also on a much bigger geographical location like forest or village.

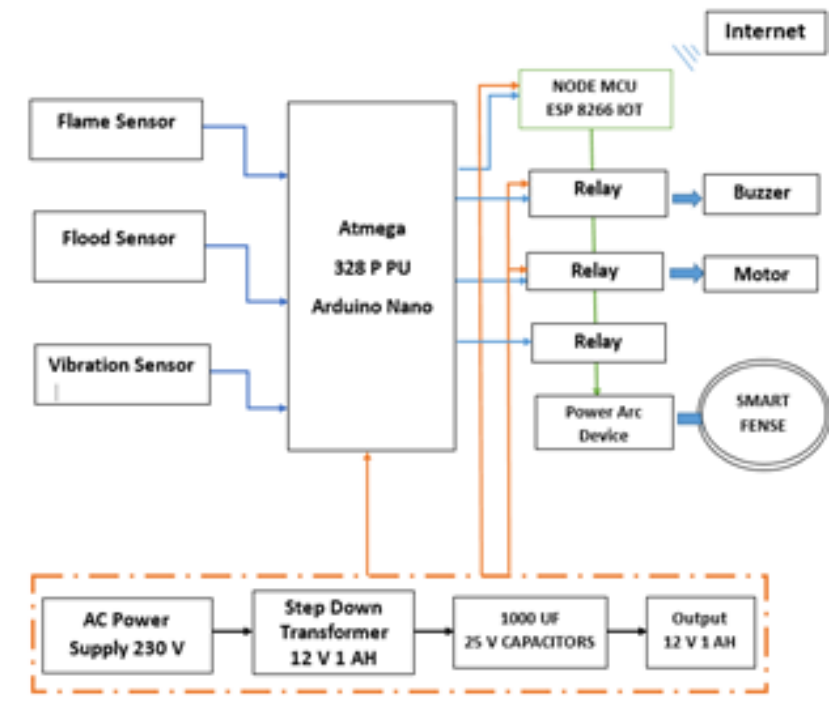

Fig. 3.2 - Overall System Block Diagram

The third disaster we deal with is the wild animal attack on common men. With the increase of population, most of the forest is being chopped down. This created the problem of food and shelter in front of animals worldwide. This makes them come to the cities and villages more often in search of food, water and shelter. Their mutual conflicts with human kill either of them often. To solve this we proposed a wire fence power with high voltage electricity. This wire fence is a smart wire fence where the current produced is not by the electricity grid. This makes the wire fence to have heavy current to give shock not intended to kill the animals. The wire fence is designed in such a way that if the group of elephant or tiger tries to enter the village then only the current activates in the fence. An additional capability of the fence is that the current in the fence can be made ON or OFF from any location all over the country using IoT technology.

To develop this paper we have designed a working model and tested it for usability.

We check it against real-time fire, Flood and animal attack conditions. In the real-time test, it was found to be working satisfactorily. This system is possible to implement in real situations to fight against the above disasters. The capabilities of sensors and Embedded System blended with the communication system is utilized efficiently. 


\section{OVERALL SYSTEM BUILDING BLOCKS}

The system design, ideal component selection and working procedure are explained in this section.

(1). Flame Sensor: - This is a sensor which excites when the flame is provided as input. This sensor is used in our project to detect the fire flame and report to Atmega microcontroller.

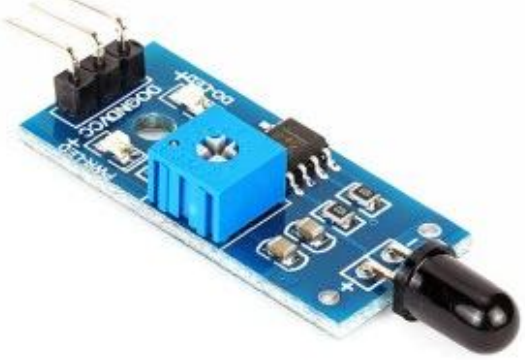

(2). Flood Sensor: - We use the limit switch as the flood switch. Whenever the water reaches to the sensor the floating ball in this shows the output high of $5 \mathrm{v}$. This alerts the microcontroller about the flood.

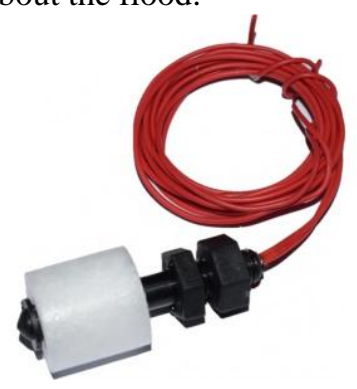

(3). Vibration Sensor: - This sensor is used to detect the vibration produced by the animals due to their heavy walk. The vibration sensor excites and gives the alert to the microcontroller.

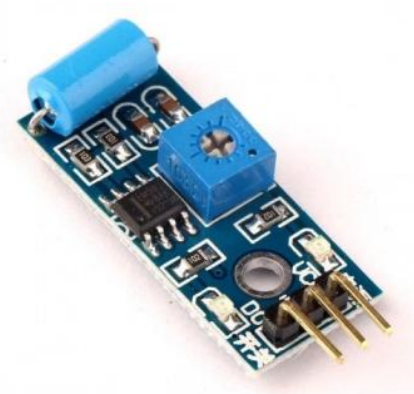

(4). Atmega 328 PPU Microcontroller: - The microcontroller is the brain of the overall system. Whenever the sensors excite, the microcontroller detects it and does the corresponding task as per the $\mathrm{C}$ program logic provided by the programmer.

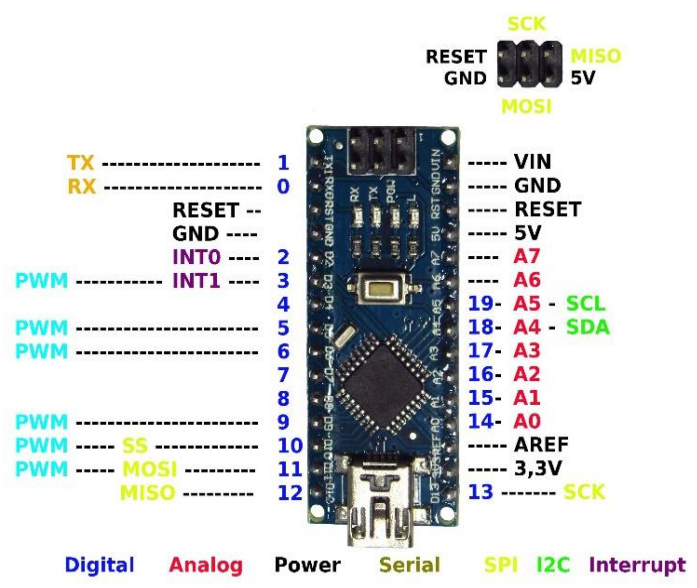

(5). IOT ESP 8266 Board: - The IoT board is responsible to update any disaster on the concerned website. The IoT board is the most powerful communication medium as it has worldwide coverage and reliability of control.

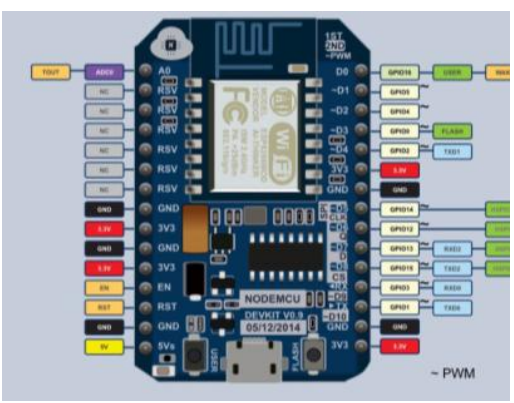

(6). Relay:- Relay is the electromagnetic switch which excites and relaxes based on microcontroller logic. Whenever we want to on the relay or off. It can be done based on the $\mathrm{C}$ program in the microcontroller.

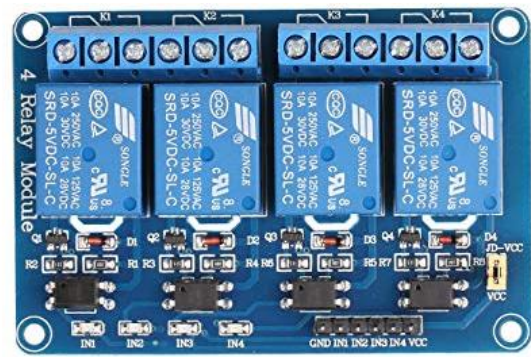

(7). Power Arc Device: - It is a power release device which exits 20000 volts by a simple 9 V DC battery. We use it to provide the live current in Smart Fence.

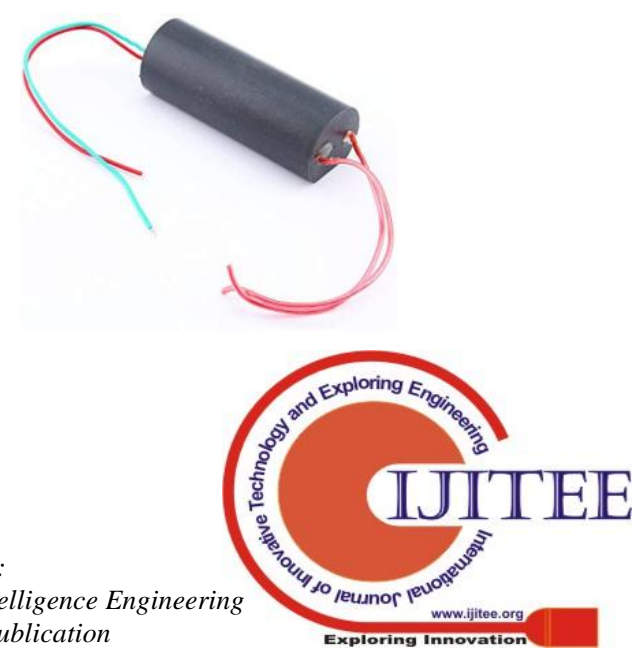




\section{A tribrid Paradigm against Inundation wild animal attack and fire disasters}

\section{IMPLEMENTATION \& RESULTS}
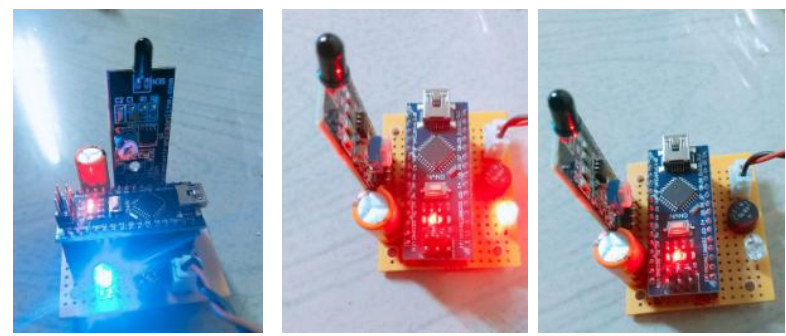

Fig. 5.1 - The implementation

\section{CONCLUSION AND FUTURE ENHANCEMENT}

Thus we developed a system of a combined approach for fire, flood and animal attack protection system. The sensor and system designed during the process are possible to be implemented in the real-time. The brain of the system is the Atmega family of the microcontroller which is designed by easy embedded $\mathrm{C}$ programming. The sensing unit is the corresponding flame, fire and flood sensing unit. The communication unit in the project is IoT web server connected unit which has worldwide coverage. This makes the system reachable to any corner of the world. Future enhancement is highly scalable for the system by adding some other disaster also in the account.

\section{REFERENCES}

1. Malaymail, (2015). Flood damage estimate tops RM 1b, 2 Jan 2015.

2. K. Endrowednes, S. Leonardy, and D. Jessie, 2010. Pre-flood Alarm Using GSM Modem, Proc. IC Tel,pp.173.

3. Endrowednes Kuantama, Leonardy Setyawan, and Jessie Darma, (2012). Early Flood Alerts Using Short Message Service (SMS), Proc. ICSET, 2012 IEEE, pp.76.

4. Izzatdin. Azyan, Nazleeni and Mazlina, (2008). Cooperative Detection Using GSMD via SMS.

5. Ping Ultrasonic Sensor datasheet, Parallax, USA. [Online], http://parallax.com.

6. Son, B., A Design and Implimintation of forest fires surveillance System Based on Wireless Sensor Netw Mountains. International Jornal of Computer Science and Network Security, 2006. 6: p. 124

7. Hafeeda, M., Bagheri, Forest Fire Modling and Early Detection Using Wireless Sensor Networks. Ad Hoc Sensor WirelessNetworks, 2009. 7: p. 169-224.

8. Scott, J. H. (2012). Introduction to Wildfire Behaviour Modeling. National Interagency Fules, Fire, \&Vegetation Technology TrWild Fire Managment RD\&A: 7-15.

9. Viegas, D. (1993). "Fire Behaviour and Fireline Safety."

10. Finney, M. A. (2004). FARSITE:Fire Area SimulaterUSDA: research parer RMRS-RP-4 Revised.

\section{AUTHORS PROFILE}

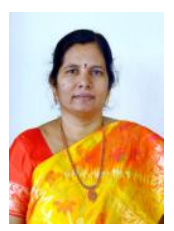

Dr B. Annapurna, Assoc. Prof. in Computer Science and Engineerig, Aditya College of Engineering, Surampalem, East Godavari Dt., AP, India. She has an excellent teaching experience of 24 years. She acquired her $\mathrm{PhD}$ from Acharaya Nagarjuna University on Data Mining Domain. She is convenor for a number of International Conferences. She organised many National seminars and Workshops. To her thrust of interest in Research she published 23 research papers on various domains in several International conferences and in International Journals.

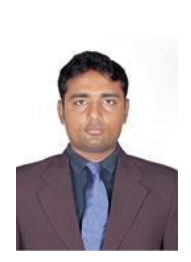

Raushan Kumar Singh is the M.Tech Gold Medalist from the department of Embedded System. $\mathrm{He}$ serves as the Technical Director of Spectrum Solutions, which is a Pondicherry, India based government approved academic event organising company. He chaired and organised several International Conferences / FDPs / Workshops / Project Expo / Guest Lectures and Robowars. He is the Editorial board member for several International Journals. He was Internationally Awarded by the First Vice President and the then Chief Justice of Supreme Court of Nepal for his excellence in Academic Events. His area of interest is immensely multidimensional.

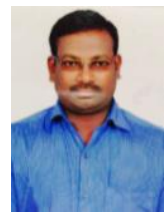

J. SARAVANAN M.E., received his B.E in Electronics and Communication Engineering from Madurai Kamaraj University and Masters in Computer and Communication from Anna University. He has National and International teaching experience of more than 15 years. He published research papers based on Embedded Systems, IoT, Image Processing etc. His own area of interest includes IoT, Wireless Communication, Digital Communications. At present he works as a lecturer in Bule Hora University, Ethiopia.

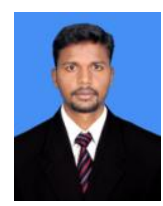

Mr.Durai Pandurangan (M.E) received his B.E (2009) in Electronics and Communication Engineering and M.E (2012) in Applied Electronics from Anna University, Tamilnadu, India. Durai Pandurangan is currently working as Lecturer in Department of Electrical and Computer Engineering, Wachemo University (WCU), Hossana, Ethiopia since Oct 2015. He has teaching experience of 8 years and advised 20 UG projects, co-advised 2 PG projects and published research papers on reputed journals and conferences. At WCU, he is working on the image enhancement techniques for weakly illuminated images. His area of interest includes Applied Electronics, Signal Processing, Communication Systems and Embedded Systems. 